\title{
Study on aesthetic psychology of the Chinese Ancient Novels
}

\author{
Weihong Zhang ${ }^{1, a}$ \\ ${ }^{1}$ Chifeng University, Chifeng 024000,China \\ a610777461@qq.com
}

Keywords: The ancient novel; Nationality; Aesthetic psychology; Study.

\begin{abstract}
The aesthetic psychology of Chinese ancient novels is closely related to the aesthetic consciousness of the subject. The aesthetic evolution of Chinese ancient novels has a deep relationship with the unique national culture of our country. It is different from any other people in the world, so it is a kind of aesthetic psychology of Chinese characteristic. The ancient novels in the development process contain Wei Jin, southern and Northern Dynasty's mystery novels, Tang, Song, Yuan, story telling script, the Ming and Qing Dynasties novels , which containing the nation of aesthetic psychology is also in constant change. The historical facts, including education, it is still interesting, such as several major features of the reunion.
\end{abstract}

\section{The aesthetic taste of the historical facts of the taste of the magic}

As everyone knows, the ancient novel was originally not to be valued by the scholars, which is unable to board the "path" of the school in good taste. Poetry and prose are the "noble" form in the traditional literature. Therefore, the literati in fiction, basically has to attach seemingly historical discourse in the creation of history was available, and it clearly indicates the a unique national aesthetic thinking. "Packing history" is the life of the big industry. The histories make men wise, one can know the history, is the literati, the people advocated work. The academic circles generally believed that the ancient novel formed in the Wei Jin Southern and Northern Dynasties period. Affected by the traditional Confucianism, Taoism and witchcraft and foreign Buddhist thought and Wei Jin Southern and Northern Dynasties Zhiguai and Zhiren novel is prosperous. By Gan Bao of Sou Shen Ji, Liu Yiqing, "Shi Shuo Xin Yu" Zhiguai and Zhiren novel point of view, on the one hand form, in a tone of "historical facts" to chronicle, on the one hand, showing the influence of superstition, witchcraft, Buddhist teachings, such as culture time synchronization is odd appreciation taste.

In the Preface of the novel Stories of Immortals ,Gan Bao said, although diligently recorded in the past records, books, including lost no matter the record, because they are not seen, heard by the writers, how can we dare to say no discrepancies with the facts?

The Sui Dynasty Evaluation of the novels of the northern and Southern Dynasties said: "the origin, the cover at the end of the wild thing," said the real chronicle. In the text of the novel, the author also does not forget to add the historical facts. "Soushenji" - capable person about Meijianchi to help the Red Knight to avenge his father myth. Still, the end of the show is not yet to show its "true". "Three songs out rotten, could not be identified, but the meat soup was, so the name 'Tomb Kings', now in your South Yichun County community." The novels of the Tang Dynasty has repeatedly shown that the mind according to, such as Li Gongzuo "Xie Xiaoe biography" said: "Yu Beixiang antecedent, the invention of the hidden text and dark on Pluto, the character in the heart. Do not know the good book, "spring and Autumn" non righteousness, a transfer to Jing beauty." Such a description, in the end of the five generation of the novel almost everywhere. Ming Dynasty Ling Yunhan cutting the light of the new preface to the cloud: "in the past Chen Hongzuo" everlasting regret biography "and the Dongcheng father biography" person the history to, salty approved. " Gan Bao although with the purpose of "invention ghosts don't accuse falsely" record of the attitude, and the spirits of the singular interest makes Soushenji fantasy of color. Fifteen volumes in the Hejian County men and women "," Garvin and "such as story of Buddhist III of marriage and the concept of reincarnation of the human life from the dead. The fantastic stories show the unique aesthetic psychology of people under the influence of Buddhism thought. Belief is 
"Soushenji" source of peculiar aesthetic psychology. People believe that the power of the gods, so often can get help and pray. "Sou Shen Ji - 2 Xiahou Hong" tells the story of the summer to see a ghost, and its communication, through communication with the ghost that the story of a recipe for abdominal pain treatment. Volume seventeen "Zhang Hanzhi" account of the ghost attached to the living body, the mouth of the living to say some people do not know the secret. The Ni Yansi "records:" suddenly see ghosts into the house, and language, diet, such as people. However, don't see ", the ghost in every corner, can observe to what was happening on earth, but also predict human life and death. The devil will do harm to people, good people to help others. Such as "volume sixteen, volume seventeen" drum "Pipa ghost" dunqiu, Vol. sixteen "Song Dingbo" buffy etc. In order to achieve the real life can not achieve the aspirations of. In fact, from the Han Dynasty, mainly from the spirits of strange things emerge in an endless stream of novels. Strange containing different smell from the name can be reflected out, such as the miraculous by "," God found postscript ", the protracted God record"; and "different", "heroic by", "realm", "Zhen Huan biography", the heterotactic biography "," the same "," wide differences in mind ", the expanding differences in mind", "progenitor differences in mind", "Luo Zhong Ji different", "Jing", the name of "God" and "different" novels until the Qing Dynasty still continue to appear, signifying "miraculous" novelist in pursuit of material for a novel, and it is generally a kind of aesthetic psychology.

\section{The"Edutainment" aesthetic psychology}

In the creation of the ancient novel, the idea of education is clearly reflected, meanwhile the works also bring the spiritual pleasure. In fact, literary works reflect and interpret the traditional culture and aesthetic concept of the Chinese people. The song and Yuan Dynasties Novels prosperity, which is closely related with the skill characteristics of the original speaker. Along with the development of urban economy, the aesthetic psychology of the general public directly accept the content of the education, and gradually change to the story of the people's life. In order to cater to the aesthetic psychology of the common people, novelists and writers are bound to create works that conform to the aesthetic object. Dominated by Confucian ethics thought of traditional culture invisible provisions of the people's behavior standard, then met the characters of this kind of thought has become the people sing the praises of the object; on the contrary, treacherous, vicious, sinister villains and villain image is the object of criticism of the mass readers. Also affected by the influence of many kinds of culture. The idea of punishing evil, evil become novelists are common psychology of creation, and combine with the enlightenment thoughts but also the public aesthetic psychology as a demand. Literary works are not boring, and the bizarre plot and winding story are the important factor to attract readers. During the Ming and Qing Dynasties novels reflect the most obvious, the most typical of the Ming Dynasty, "San Yan", "Er Pai". From the visible names of three short stories, "Yushi Mingyan", "Jingshitongyan", and "Xingshihengyan" we can see the author gives the deep meanings. So entertaining is a manifestation of ancient novels in aesthetic psychology.

\section{The design of Advocating the successful outcome}

"Circle" is a symbol of unity. Since ancient times, people in the shape of a circle, and later extended to the meaning of harmony. By the "circle" extended out of a variety of meanings in the ancient literary narrative works reflect the harmony between man and nature, the outcome of a successful narrative characteristics. Ancient drama, happy ending to the story many, the influence of ancient culture and the traditional the people formed a happy, happy national aesthetic psychological tendency. The aesthetic tendency in the ancient novels also show, such as the legend of the Tang Dynasty "Liuyi biography" has a complete at the end of the story. The famous Ming Dynasty Vernacular Short stories set "San Yan Er Pai" is more than a reaction. But Zhanghui novels narrative structure in tail echo, structural characteristics of the cycle of the manners and morals of the time, it is round the deep aesthetic psychology confirmed. 
"A dream of Red Mansions" in Jia Baoyu and Lin Daiyu in past lives were stone and immortality, for years only because of the essence of heaven and earth, infiltration, only the spiritual. Just because it is a past life, in the world after experiencing or return to the initial state of the debt, to the reader a complete account of the. Of course, the author used the past and present in Buddhism, the idea of karma. "Water Margin" in the one hundred single eight, also should be one hundred and eight stars to heaven. Hong Wei release was suppressed for hundreds of years in the "Buddha Temple, so the Huizong in Liangshan during the one hundred single eight. "Outlaws of the marsh" that starts with the design and later Song Jiang, who died after being emperor Fengshen echo from afar, the completed the narrative strategy of relatively complete, show the ancients contains philosophical grand ingenious. Myth thinking is a common mode of ancient novels, the author uses the myth story is nothing more to attract readers, more in line with the reader's aesthetic habits. The head and tail penetration, return to the origin of the narrative structure more shows that the use of abstraction "round" national aesthetic thinking in many cultural blend, the western novels and often from a view of a person and a thing to write is quite different.

Although the basic role of the novel is to entertain, in the process of development due to the traditional culture, in order to find a "proper" of the novel, the historical facts of the coat will be decorated. However, its unique aesthetic taste of the public still can reveal it. Confucianism dominated under the influence of traditional culture, the round of collective aesthetic tendencies and preferences with the aesthetic psychology of education meaning the amusing story is the ancient novels containing the nationalization.

\section{References}

[1] M.L. Feng.Sanyan, Hubei people's publishing house, 1996.5.

[2] M.C. Ling.Er Pai, Hubei people's publishing house, 1996.4.

[3] Y. Yang. Yang Yi 'first volume, China narrative . people press 2004.2

[4] M.J. Cai, C.X. Zhang,The cultural interpretation of the aesthetic evolution of Chinese ancient novels . Shandong social science 2005.11.

[5] X.R. Yang.The aesthetic standard of Chinese ancient novel. Journal of Liaoning University 1993.6.

[6] P. Yan.On Chinese ancient novel aesthetic thought is exhorted. Journal of Zhengzhou University 2001.9. 